\title{
Babaların Gözünden Anne Bekçiliği: Bir Ölçek Uyarlama Çalışması
}

\author{
DOI: 10.26466/opus. 724644 \\ $*$

\begin{abstract}
Güleycan Akgöz Aktaș - Arzu Aydın **
* Araştırma Görevlisi, Mersin Üniversitesi, Fen Edebiyat Fakültesi, Mersin/Türkiye E-Posta: glycnakgoz@gmail.com ORCID: 0000-0002-5681-7496

** Doç.Dr., Mersin Üniversitesi, Fen Edebiyat Fakültesi, Mersin/Türkiye

E-Posta: arzu.aydin@mersin.edu.tr

ORCID: $\underline{0000-0002-3047-0308}$
\end{abstract}

\begin{abstract}
Öz
Annelerin, eşlerinin çocuk katılımına yönelik kolaylaştırıcı ve zorlaştırıcı davranışları anne bekçiliği olarak tanımlanmaktadır. Bu çalışmanın amacı anne bekçiliği davranışlarını babaların gözünden değerlendiren bir ölçeğin Türkçeye uyarlanmasıdır. Bu kapsamda eşlerin birbirinden algıladığı teşvik edici, kontrolcü ya da engelleyici bekçilik davranışlarını değerlendirmek için Puhlman ve Pasley (2017) tarafindan geliştirilen Anne Bekçiliği Ölçeği'nin Baba Formu'nun (ABÖ-B) geçerlik güvenirlik çalışmaları yürütülmüş̧ür. Çalışmaya 3 ile 7 yaş arasında en az bir çocuğu olan toplamda 255 evli baba katılmıştır. Sonuçlar ABÖ-B'nin orijinal 3 boyutlu yapısını koruduğunu ve geçerlik güvenirlik açısından uygun indekslere sahip olduğunu göstermiştir. Babaların eşlerinden algıladığı teşvik düzeylerinin baba katılımı ile pozitif yönlü, algılanan engel ve kontrol bekçilik düzeylerinin ise baba katıllımı ile negatif yönlü ilişkili olduğu bulunmuştur. Bununla birlikte algilanan bekçilik türleri bazı demografik özellikler ile (çocuk sayısl, cinsiyeti gibi) ilişkilidir ve babalar en çok geleneksel sınır koyucu bekçilik alt türünü algıladıklarını bildirmiştir. Babaların olumlu ve olumsuz bekçilik davranışlarımı algıllayışlarım ortaya çıkaran mevcut çalışmanın bulguları, baba katılımının ve aile sisteminde uyumun teşvik edilmesi için önemli bulunmaktadir.
\end{abstract}

Anahtar Kelimeler: anne bekçiliği, babaların algıladığı anne bekçiliği, baba katılımı, geçerlik, güvenirlik 


\title{
Maternal Gatekeeping from Fathers' Perspectives: A Scale Adaptation Study
}

\begin{abstract}
Facilitating and hindering behaviors of mothers regarding their spouse's participation in their children are defined as maternal gatekeeping. The aim of this study is to adapt a scale that evaluates maternal gatekeeping behaviors from perceptions of fathers. In this context, the validity and reliability of the Father Form of the Maternal Gatekeeping Scale (MGS) developed by Puhlman and Pasley (2017) to evaluate the encouragement, discouragement and control behaviors to parent perceive from each other was examined. A total of 255 married fathers with at least one child between the ages of 3 and 7 participated in the study. The results showed that MGS-F preserves its original three dimensions structure and has appropriate indexes in terms of validity and reliability. It was found that the encouragement levels perceived by fathers from their spouses were positively related with the father involvement, and the perceived control and discouragement levels were negatively related to the father involvement. However, perceived types of maternal gatekeeping behaviors are associated with some demographic characteristics (such as the number of children, gender), and fathers reported that they perceived traditional sub-categories of maternal gatekeeping the most common. Findings of the current study, which reveals the perceptions of fathers' positive and negative maternal gatekeeping behaviors are important for encouraging father involvement and adaptation in the family system.
\end{abstract}

Keywords: maternal gatekeeping, fathers' perceptions of maternal gatekeeping, father involvement, validity, reliability 


\section{Giriş}

Geçtiğimiz son 50 yıla kadar babalar, çocuk gelişimi araştırmalarında öncelikli olarak yer almazken, aile yapısı ve aile içi rollerde yaşanan değişimler özellikle babaların ev içindeki işlere katılımları ile annelerin söz konusu değişimlere nasıl ayak uydurduğu konusunu önemli kılmıştır. Aile içindeki bu sosyal dönüşümün kanıtı olarak, günümüzde babaların çocuklarıyla çok daha sık vakit geçirdiğini (Pleck ve Masciadrelli, 2004) ve önceki kuşaklara göre birlikte ebeveynlik (coparenting) için daha istekli oldukların gösteren çalışmalar (Henwood ve Procter, 2003) bulunmaktadır. Buna karşın bazı araştırmalar, daha fazla bakım ve destek veren bu yeni babalık anlayışının (new nurturant fathering) gerçekte görülebilir olmadığını, annelerin çocuk bakım görevleri için eşlerinden çok daha fazla zaman harcadığını (Carrillo, Bermudez, Suarez, Gutierrez ve Delgado, 2016), annelik görevlerini yerine getirmenin haftanın her günü 14 saat çalışılan bir işe bedel olduğunu bildirmektedir (Petter, 2018). Babaların ebeveynlik pratiklerine odaklanan çalışmalarda, baba katılımının çok boyutlu bir yapı göstermesine rağmen çocukla kurulan ilişkilerde sıklıkla oyun oynama davranışı olarak gözlendiği (Paquette, 2004); duyarlık, sıcaklık gibi kavramların ise sıklıkla anne-çocuk ilişkisi özelinde incelendiği görülmektedir (Carrillo, Bermudez, Gutierrez, Camilla ve Delgado, 2016; Kiang, Moreno ve Robinson, 2004).

Baba katılımı, tanımlamalarında da belirtildiği gibi, baba ve çocuk arasındaki karşılıklı etkileşimin varlığını ve bu etkileşimin başta çocuk üzerindeki olmak üzere aile sistemindeki etkilerini temsil etmektedir (Cabrera, Fitzgerald, Bradley ve Roggman, 2007; Cox ve Paley, 2003). Araştırmalar babaların çocuklar üzerindeki rolünü gittikçe daha çok vurgulamaktadır (Fogarty ve Evans, 2009). Örneğin Downer, Campos, McWayne ve Gartner (2008), baba katılımının çocukların akademik ve sosyo-duygusal özellikleriyle ilişkili olduğunu ortaya koymuştur. Benzer şekilde, baba katılımı daha düşük düzeylerde davranış problemi (Kennedy, Betts, Dunn, Sonuga-Barke ve Underwood, 2015) ve daha sağlıklı arkadaşlık ilişkileri (Sarkadi, Kristiansson, Oberklaid ve Bremberg, 2008) ile ilişkilidir. Baba katılımının çocuk gelişimi üzerindeki doğrudan etkileri kadar, babaların çocuk üzerindeki destekleyici davranışlarının anneyi, dolaylı olarak da çocuğu etkilediğini gösteren çalışmalar da bulunmaktadır (Jia ve Schoppe-Sullivan, 2011; Lamb, 2000). Diğer bir ifadeyle babanın çocuğa sağladığı destek, annelerin algıladığı eş desteği 
aracilığıyla çocuğu etkilemektedir. Çoğu çalışma algılanan eş desteğinin olumlu yönlerinden bahsederek, çocuklar üzerinde etkili bir ebeveynlik gösterilmesinde yardımc olduğunu vurgulamaktadır (Allen ve Daly, 2007; Downer ve Mendez, 2005; Durrett, Richards, Otaki, Pennebaker ve Nyquist, 1986). Oysa bazı çalışmalar artan baba katılımının ve desteğinin, annelik rolüne ilişkin yetersizlik duygusuna yol açabileceğini (Lamb, Pleck ve Levine, 1985), dolayısıyla annelerin kendi uzmanlık alanı olarak gördükleri çocuk yetiştirme pratiklerinde babaları kısıtlayabileceğini bildirmektedir (Hawkins ve Dollahite, 1997; Puhlman ve Pasley, 2013). Babalar çocuklarının yaşamına dahil olurken, baba-çocuk ilişkisine yön veren annelerin, eşlerine karşı uyguladıkları bu kolaylaştırıcı ya da zorlayıcı davranışlar anne bekçiliği kavramı ile değerlendirilmektedir.

Çalışılmaya başlandığı ilk zamanlarda (Allen ve Hawkins, 1999; DeLuccie, 1995), 'ev işleri konusunda babalar üzerinde olumsuz etki bırakan anne davranışları' olarak tanımlanan anne bekçiliğinin günümüzde kapsam olarak genişletildiği görülmektedir (Fagan ve Barnett, 2003; Walker ve McGraw, 2000; Schoppe-Sullivan, Brown, Cannon, Mangelsdorf ve Sokolowski, 2008; Puhlman, 2013). Anne bekçiliğini aile sistem teorisi ve feminist kuramların görüşlerini birleştirerek inceleyen Puhlman ve Pasley (2013), anne bekçiliğine ilişkin yeni bir model sunarak üç alt boyut belirlemişlerdir. Boyutlardan biri olan teşvik, bekçiliğin babalar üzerindeki kolaylaştırıcı etkilerine vurgu yapar. Teşvik edici anneler çocukla ilgili konularda eşleriyle işbirliği yapan, babanın çocuk için önemini bilen ve bunu babaya hissettiren, memnuniyet ifadeleri ile övgüde bulunan, baba odaklı ritüelleri (babanın doğum günü gibi) önemseyen, destekleyici beden diline sahip ve eşi hakkında olumlu konuşan tarzda bekçilik davranışları sergiler (Puhlman ve Pasley, 2013). Eş desteğini olumlu algılayan teşvik edici annelerin, genel olarak baba katılımı sürecini kolaylaştırdığı, desteklediği ve geliştirdiği bilinmekle birlikte (Pedersen ve Berman, 1987); bazı araştırmalarda teşvik edici bekçiliğin baba katılımını artırmadığı (Akgöz-Aktaş, 2017; Van Egeren ve Hawkins, 2004) bulunmuştur. Daha ayrıntılı bir ifadeyle bazı araştırma sonuçlarında, yüksek düzeyde teşvik etmenin baba katılımı düzeyinde bir fark yaratmadığı; ancak düşük düzeyde teşviğin baba katılımını bozduğu bildirilmektedir (Altenburger, Schoppe-Sullivan ve Dush, 2018; Dickie, 1987). Söz konusu mekanizmayı açılamaya çalışan araştırmacılar, teşvik ediciliğin anne ve babalar tarafından farklı şekilde algılanabileceği üzerinde durmaktadır (Altenburger vd., 2018; 
Fagan ve Cherson, 2015;). Dolayısıyla babaların anne bekçiliği davranışlarını nasıl algıladığının incelenmesi, olumlu bekçilik davranışlarının olası etkilerini anlamak için önemlidir.

Bir diğer boyut olan engel, babaların çocuk bakımı alanındaki yerini kısıtlayan, görmezden gelen anne davranışlarını içerir. Engelleyici anneler babaçocuk etkileşimini bölerek, babanın çocuk bakım davranışlarını eleştirerek, eşin ebeveynlik kararlarını baltalayıp desteklemediği halde destekliyormuş gibi görünerek, alaycı ifadelerle açıkça ya da gizli biçimde babayı kötüleyerek bekçilik yaparlar (Puhlman ve Pasley, 2013). Baba katılımını ve evlilik ilişkisini olumsuz yönde etkilediği bilinen engelleyici bekçiliğin aynı zamanda anneye ait bazı değişkenlerle (depresyon, evlilik uyumu gibi) ilişkili olduğu bilinmektedir (Gaunt, 2008).

Puhlman ve Pasley'in (2013) anne bekçiliği kavramsallaştırmasında yer alan kontrol ise, aile içinde bilgi, enerji, kaynak ve sınır yönetimi ile düzenleme ve planlama girişimlerinin nihai karar merci olmayı ifade eden boyuttur. Olumlu ya da olumsuz koşulları ifade etmeyen kontrolcü davranışlar, annenin baba-çocuk etkileşimini denetleme yoğunluğuna atıf yapar. Dolayısıyla kavrama ilişkin ortaya atılan yeni modelde anne bekçiliği, çocuk bakımı alanını da kapsayan ve yalnızca engelleyici olmayan davranışlar bütünü olarak görülmektedir.

Söz konusu kavramsallaştırmada araştırmacılar, kararlı (polarized mothers-baba katılımı konusunda lehte ya da aleyhte bir tercihi açıça gösteren anneler) ve kararsız annelik (ambivalent mothers-baba katılımı konusunda kafa karıştırıc ve tutarsız tercihler gösteren anneler) sınıflamalarının altında teşvik, engel ve kontrol boyutlarının yüksek ve düşük düzeylerinin çaprazlanmasına dayanarak sekiz alt türde bekçilik davranışı (geleneksel sınır koyucu, pasif engelleyici, kolaylaştırıc1, pasif kolaylaştırıc1; tutarsız yönetici, duyarsız, başına buyruk, gözlenmeyen) belirlemişlerdir. Baba katılımına etki eden anne davranışlarındaki bu çeşitlilik, özellikle cinsiyet rolleri bağlamında incelenmektedir (Kuo, Volling ve Gonzalez, 2018; Puhlman, 2013). Cinsiyet eşitliğini benimsemiş eşlerin ev işlerini ve çocuk bakımın paylaşma konusunda daha ortak hareket ettiği, dolayısıyla evlilik ilişkisi ve ebeveynlik konularında birbirlerini besledikleri bildirilmektedir (Kuo, Volling ve Gonzalez, 2018; Lavee ve Katz, 2004). Konuya ilişkin sınırlı sayıdaki çalışmada, cinsiyet rollerinin geleneksel olduğu ülkelerde babaların çocuk bakımına daha az ka- 
tıldığı bildirilmektedir (Pekel-Uludağl1, 2019; Silverstein, Auerbach ve Levant, 2002). Dahası baba-çocuk ilişkisindeki kısıtlılığın babaların çocukla ilgili konularda yetkinlik alanlarını dar görmelerinden kaynaklandığına ilişkin bulgular mevcuttur (Bouchard, Lee, Asgary ve Pelletier, 2007). Böyle olduğunda babaların eş desteğine daha çok ihtiyaç duydukları tahmin edilmektedir (Pekel-Uludağlı, 2019); çünkü annelerin olumlu ve olumsuz birtakım davranışlarının, babaların ev işlerine ve çocuk bakımına katılım sağlayabilmelerinde önemli etkileri olduğu bilinmektedir (Fagan ve Barnett, 2003; Puhlman ve Pasley, 2017). Öyle ki McBride ve arkadaşları (2015) babaların ebeveynlik davranışlarının babaların kendilerinden çok eşlerinin etkisiyle şekillendiğini bildirmişlerdir. Eşler arasındaki ilişkinin niteliği zayıfladığında, babaların çocuklarına destek vermekten çekildikleri ve bozulan eş ilişkisi kadar, baba-çocuk etkileşiminin de sınırlandığı belirtilmektedir (Amato ve King, 2007; Cummings, Goeke-Morey ve Raymond, 2004; Hoffmaster, 2006; Hawkins). Baba kırılganlı̆̆ı olarak anılan söz konusu hipotez, annelerin baba-çocuk ilişkisindeki kritik rolünü vurgulamaktadır.

Literatürde baba katılımına etki edeceği öngörülen çocuğa ilişkin bazı değişkenlerden bahsedilmektedir. Örneğin baba katılımı, küçük ve büyük yaştaki çocuklar için farklılaşmaktadır (Evenson ve Simon, 2005). Bununla birlikte artan çocuk sayısının babanın ilgisini eşit dağıtamamasına bağlı olarak katılımını azaltabileceği (Mehall, Spinrad, Eisenberg ve Gaertner, 2009) ya da çocuk sayısı ile birlikte artan iş yükünün eşit paylaşılmasına bağlı olarak katılımı artırabileceği (Ishii-Kuntz, Gomel ve Tinsley, 2010) bildirilmiştir. Baba katılımını farklılaştıran bir özellik de çocuğun cinsiyeti olarak sunulmuştur (Mehall, Spinrad, Eisenberg ve Gaertner, 2009). Baba katılımını farklılaştıran çocuğa ait bu özelliklerin evlilik ilişkisinin kalitesinden (Akgöz-Aktaş, 2017), anne bekçiliğinden (Schoppe-Sullivan vd.,2008), ebeveyn yaşından (Marsiglio, 1993) etkilendiği biliniyor olsa da; baba-çocuk ilişkisine dair sonuçların babaların bekçilik algısına göre nasıl şekillendiğine dair bilgilerimiz kısıtlıdır.

Yürütülen önceki bekçilik çalışmalarında, sonuçların sıklıkla annelerin kendi bildirimine (Allen ve Hawkins, 1999; Fagan ve Barnett, 2003) ya da birleştirilmiş anne ve baba görüşmelerine (Meteyer ve Perry-Jenkins, 2010; Schoppe-Sullivan, Brown, Cannon, Mangelsdorf ve Sokolowski, 2008) dayandığı görülmektedir. Yalnızca Adamson 2010'daki bir çalışmasında, ana babalık davranışlarını Kimlik Kuramı çerçevesinde incelemiş ve orta ölçekli (midrange) bir model önererek, babaların anne bekçiliğinden etkilenmesinin 
kendi algılarına göre farklılaşabileceğini, dolayısıyla annelerden algılanan bekçiliğin babaların ebeveynlik pratiklerine farklı biçimlerde yansıyacağını öngörmüştür. Ardından Puhlman 2013'teki çalışmasında, bekçilik davranışlarına ilişkin anne ve babalardan ayrı ayrı bildirim alarak, o zamana dek benzeri bulunmayan bir sonuç paylaşmış, anne ve babaların bekçilik davranışlarına ilişkin algılarının tam olarak aynı olmadığı görüşünü güçlendirmiştir. Sonuca göre araştırmacı, geliştirdiği bekçilik davranışına ilişkin ölçüm modelinin anne ve babalar için farklılaştığını bildirmiştir. Anne Bekçiliği Ölçeği boyutlar açısından (teşvik, engel ve kontrol) ebeveynlerin her ikisi için aynı kalsa da, boyutları temsil eden maddeler açısından farklılaşmıştır. Puhlman (2013), babaların engel olarak algıladığı bazı maddelerin anneler için aynı boyutu oluşturmadığına özellikle dikkat çekmiştir.

Yerel literatürde ise; anne bekçiliği kavramının henüz yeni yeni çalışılmaya başlandığı (Aydın ve Akgöz-Aktaş, 2017; Çoban, 2017; Gazi, 2019; Kurşun, 2019), dolayısıyla kavrama ilişkin ölçüm araçlarının sınırlı sayıda olduğu görülmektedir. İlk kez Karabulut ve Şendil (2017), Fagan ve Barnett' in (2003) Anne Bekçiliği Ölçeği'ni Türkçeye uyarlamışlardır. Araştırmacılar anne bekçiliğini, lise birinci ve ikinci sınıfa giden çocukların babalarının gözünden değerlendirebilmek için orijinal ölçek maddelerini babalara uygulanabilir hale getirmişlerdir. Ardından Akgöz-Aktaş ve Aydın (2020), Puhlman ve Pasley'in (2017) geliştirmiş olduğu Anne Bekçiliği Ölçeği-Anne Formu'nun geçerlik ve güvenirliğini incelemişlerdir. İlgili çalışma Akgöz-Aktaş'ın (2017) yüksek lisans çalışmasında 3 ile 6 yaş arasında çocuğu olan annelerin bekçilik davranışlarını değerlendirmek için kullandığı uyarlama maddelerini içermektedir.

Bu çalışmanın öncelikli amacı, anne bekçiliğinin babaların gözünden değerlendirilebileceği geçerli ve güvenilir bir ölçüm aracının Türkçeye uyarlanarak literatüre kazandırılmasıdır. Bu amaçla Puhlman ve Pasley'in (2017) Anne Bekçiliği Ölçeği'ni geliştirirken (The Maternal Gatekeeping Scale) oluşturduğu baba formunun psikometrik özellikleri sınanmıştır. Söz konusu ölçeğin, annelerin bekçilik davranışlarının babaların gözünden kapsamlı biçimde değerlendirilmesine yardımcı olacağı düşünülmektedir. Ayrıca, çalışmanın ölçüt bağıntılı geçerliği için kullanılan baba katılımı değişkeninin, babaların algiladığı anne bekçiliği ile ilişkili olarak, babaların çocuğun yaşamına dahil olmaları hakkında bilgi vereceği düşünülmektedir. Son olarak, litera- 
türde teori olarak sunulan bazı bilgilerin sınanması amaciyla babaların alg1ladığı bekçiliğin bazı demografik özelliklerle ilişkisinin incelenmesi, bu çalışmanın amaçlarındandır.

\section{Yöntem}

\section{Katilımcilar}

Çalışmanın katılımcılarını 3 ile 7 yaş arasında (Ort. $=4.57$, SS=1.22) çocuğu olan toplam 255 baba oluşturmuştur. Babaların yaşları 24 ile 55 arasında değişmektedir (Ort. $=37.02, \mathrm{SS}=5.52$ ) ve tümü ortalama 10 senedir evli olduklarını bildirmiştir. Sahip oldukları çocuk sayısı 1 ile 8 arasında değişen babaların çocuklarının $128^{\prime} \mathrm{i}$ kız (\%50.2) ve 127'si erkektir (\%49.8). Babaların $26^{\prime}$ sı son mezuniyetini lisansüstü, 130'u üniversite, $65^{\prime}$ i lise ve 34'ü ilkokul-ortaokul olarak bildirmiştir. Babaların eşlerine ilişkin bildirdiği eğitim düzeylerine göre ise; 26 anne lisansüstü, 129 anne üniversite, 42 anne lise ve 58 anne ilkokul-ortaokul mezunudur.

\section{İşlem}

Çalışmada, daha önce Akgöz-Aktaş (2017) tarafından Türkçeye uyarlanmış olan Anne Bekçiliği Ölçeği-Anne Formu'nda yer alan maddeler, alanda uzman akademisyenler tarafından babaların cevaplayacağı biçimde düzenlenmiştir. Düzenlenen ölçek maddelerinin anlaşılırlığından emin olmak için, okul öncesi dönemde çocuğu olan 15 babadan ölçek maddelerini doldurmaları istenmiştir. Babalardan alınan dönütlerin ardından yapılan düzenlemeler sonrası ölçeğe son hali verilmiş, ardından katılımcıların cevaplayacağı ölçek formları oluşturulmuştur. Ölçek formları kartopu örnekleme yoluyla 3 ile 7 yaş arasında en az bir çocuğu olan, evli ve çalışma için gönüllü babalara ulaştırılmıştır. Katılımcıların çalışmadan çekilme hakları kendilerine bildirilmiş, tüm süreç 25.04.2019-021 kodlu etik izin kapsamında yürütülmüştür.

\section{Ölçüm Araçları}

Demografik Özellikler için Bilgi Formu: Çalışmada babaların cevapladığı demografik özelliklere ilişkin yedi soru bulunmaktadır: ebeveyn yaşı, eğitimi, evlilik süresi; çocuk yaşı, cinsiyeti, doğum sırası ve kardeş sayısı. 
Anne Bekçiliği Ölçeği: Annelerin babalar üzerindeki teşvik edici, kontrolcü ve engelleyici davranışlarını değerlendirmek amacıyla; babalardan Puhlman ve Pasley'in (2017) geliştirdiği Anne Bekçiliği Ölçeği-Baba Formu'nu (ABÖ-B) doldurmaları istenmiştir. Ölçek orjinalinde 42 maddeden ve üç alt boyuttan oluşmaktadır. Araştırmacılar geçerlik ve güvenirlik analizi sonunda 15 maddelik, 5'li Likert tipinde (0-Asla ve 5-Her Zaman arasında değişen) bir ölçek formu geliştirmişlerdir. Mevcut çalışmada analizler 42 madde üzerinden yürütülmüş ve 33 maddelik, 3 boyutlu [teşvik (10 madde; örn., "Eşim çocukla oyun oynama şeklimi destekler."; Cronbach Alpha = .82); kontrol (10 madde; örn., "Eşim çocukla geçirdiğim zamanı denetler."; Cronbach Alpha = .77 ve engel (13 madde; örn., "Eşim çocuğa anne babalık yapma konusunda benimle tartışmaktan kaçınır."; Cronbach Alpha = .85)] bir ölçek elde edilmiştir. Ölçek maddelerinin her biri 5’li Likert tipi ile puanlanmaktadir.

Baba Katılımı Ölçeği: Babalardan, kendi ebeveynlik davranışlarını değerlendiren Baba Katılım Ölçeği'ni (BAKÖ) (Sımsıkı ve Şendil, 2014) doldurmaları istenmiştir. Ölçek 37 maddeden ve üç alt boyuttan oluşmaktadır: keyfi meşguliyet (17 madde; örn., "Çocuğuma kitap okurum."; Cronbach's Alpha = .85), temel bakım (8 madde; örn., "Çocuğuma banyo yaptırırım."; Cronbach's Alpha = .80 ) ve ilgi ve yakınlık (12 madde; örn., "Çocuğuma sarılırım."; Cronbach's Alpha $=.73$ ). Ölçek maddelerinin her biri 5'li Likert tipi ile puanlanmakta ve baba katılımına ilişkin toplam puan kullanılabilmektedir. Orijinal çalışmada araştırmacılar ölçekten elde edilen toplam puanın Cronbach Alfa güvenirlik katsayısını .92 olarak vermişlerdir. Mevcut çalışmada BAKÖ toplam puanına ilişkin Cronbach Alfa güvenirlik katsayısı .90 ve alt boyutlara ilişkin katsayılar sırasıyla $.86, .80$ ve .74 olarak bulunmuştur.

\section{Bulgular}

Doğrulayıcı Faktör Analizi (Yapı Geçerliği): Çalışma kapsamında uyarlanan ABÖ-B'nin orijinal faktöriyel yapısını test etmek amaciyla Lisrel 8.51 programı kullanılarak doğrulayıcı faktör analizi (DFA) yürütülmüştür. Puhlman (2013), çalışmasındaki örneklemin homojen bir yapıda olmasını sınırlılık olarak sunarak, her yeni çalışmada tüm maddelerin yeniden sınanmasının faydalı olacağını bildirdiğinden mevcut çalışmada DFA 42 madde üzerinden 
yürütülmüştür. Analiz sonucunda bazı maddelerin madde yüklerinin çok düşük (<.30) olduğu $(5,12,13,16,22,27,37,38,40)$ tespit edilmiştir. Sorunlu maddeler çıkarıldığında kalan 33 madde ile (teşvik 10, kontrol 10 ve engel 13 madde) tekrarlanan analizde uyum indekslerinin kabul edilebilir sınurlar içinde olduğu görülmüştür $(\chi 2[517, \mathrm{~N}=255]=1171.06, \chi 2 / s d=2.26, \mathrm{RMSEA}=$ $.06, \mathrm{GFI}=.85, \mathrm{AGFI}=.80, \mathrm{CFI}=.88$ ). Analizde engel ve kontrol boyutları arasinda pozitif yönlü yüksek korelasyon $(\mathrm{r}=.86, \mathrm{p}<.001)$, engel ve teşvik boyutları arasında negatif yönlü yüksek düzeyde korelasyon $(\mathrm{r}=-.77, \mathrm{p}<.001)$ ve kontrol ile teşvik boyutları arasında negatif yönlü orta düzeyde korelasyon $(\mathrm{r}=-.55, \mathrm{p}<.05)$ olduğu bulunmuştur. Modele ilişkin doğrulayıc faktör analizi sonuçları Şekil 1'de görülmektedir. 

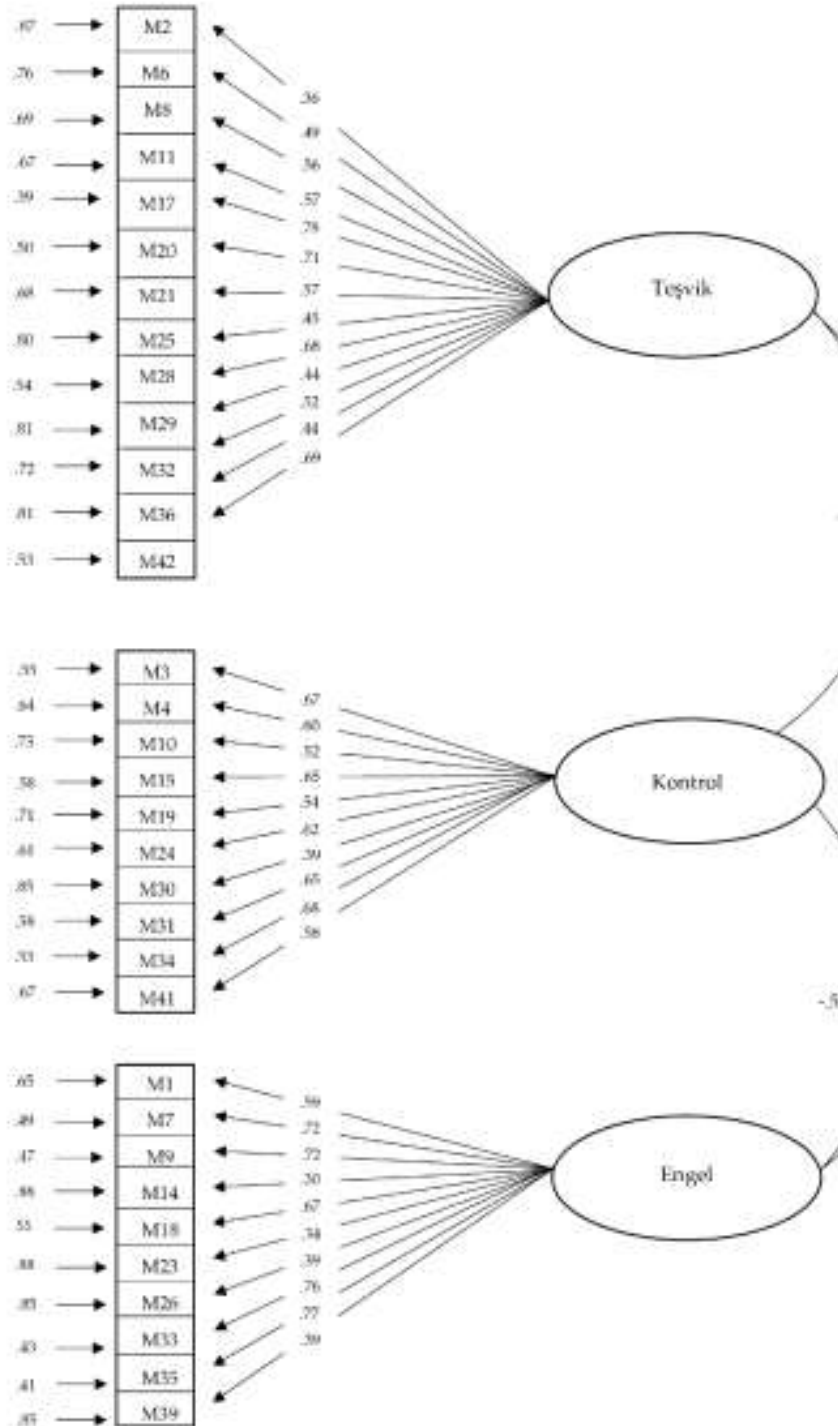

Ss
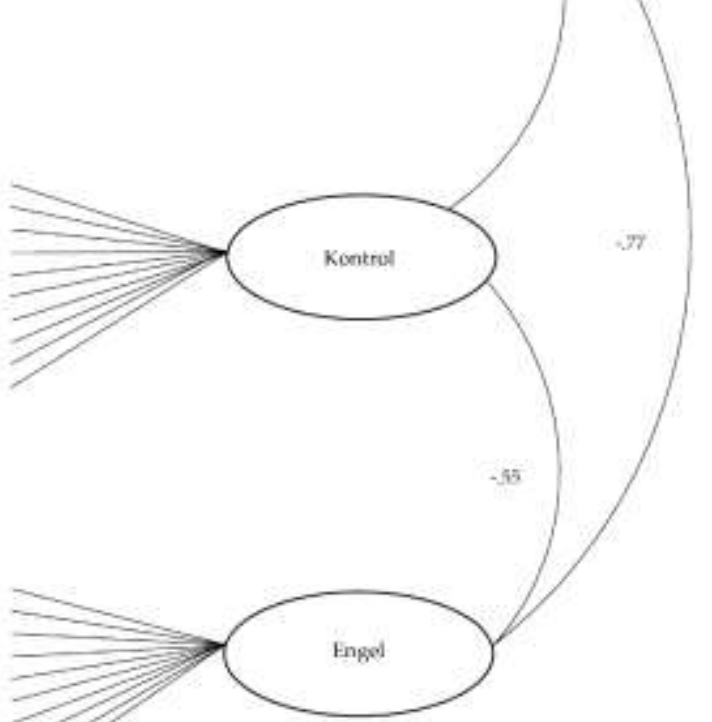

Şekil 1. Babaların algıladığı anne bekçiliği türlerinin doğrulayıcı faktör analizi 
Betimsel İstatistikler: Çalışmada kullanılan tüm değişkenlere ilişkin ortalama, standart sapma ve korelasyon değerleri Tablo 1.'de görülmektedir.

Tablo 1. Tüm değişkenlerin ortalama, standart sapma ve korelasyon değerleri

\begin{tabular}{|c|c|c|c|c|c|c|c|c|}
\hline & Ort. (SS) & BAKÖ & KM & $\dot{\bar{I} Y}$ & $\mathrm{~TB}$ & Teşvik & Kontrol & Engel \\
\hline BAKÖ & $\begin{array}{l}143.96 \\
(19.04)\end{array}$ & 1.0 & & & & & & \\
\hline KM & $\begin{array}{l}59.67 \\
(11.07)\end{array}$ & $.93^{* *}$ & 1.0 & & & & & \\
\hline$\overline{\mathrm{IIY}}$ & $\begin{array}{l}55.76 \\
(4.27) \\
\end{array}$ & $.72^{* *}$ & $.58^{* *}$ & 1.0 & & & & \\
\hline TB & $\begin{array}{r}28.53 \\
(6.87) \\
\end{array}$ & $.82^{* *}$ & $.61^{* *}$ & $.45^{* *}$ & 1.0 & & & \\
\hline Teşvik & $\begin{array}{l}58.36 \\
(9.6) \\
\end{array}$ & $.51^{* *}$ & $.47^{* *}$ & $.44^{* *}$ & $.38^{* *}$ & 1.0 & & \\
\hline Kontrol & $\begin{array}{l}20.12 \\
(11.56)\end{array}$ & $-.25^{* *}$ & $-.17^{* *}$ & $-.16^{* *}$ & $-.33^{* * *}$ & $-.24^{* *}$ & 1.0 & \\
\hline Engel & $\begin{array}{l}18.32 \\
(11.37)\end{array}$ & $-.24^{* *}$ & $-.14^{*}$ & -.22 & $-.29^{* *}$ & $-.35^{* *}$ & $.72^{* *}$ & 1.0 \\
\hline
\end{tabular}

${ }^{*} \mathrm{p}<.05^{* *} \mathrm{p}<.001$

BAKÖ - baba katılımı, KM - keyfi meşguliyet, IYY - ilgi ve yakınlık, TB - temel bakım

Ölçüt Bağıntılı Geçerlik (Kriter Geçerliği): Ölçüt bağıntılı geçerlik kapsamında Anne Bekçiliği Ölçeği Baba Formu'nun Baba Katılımı Ölçeği (BAKÖ) ile arasındaki korelasyon değerleri incelenmiştir. Bulgular BAKÖ toplam puanı ile ABÖ-B teşvik alt boyutu arasında pozitif yönlü bir ilişkiye ( $\mathrm{r}=51$, $\mathrm{p}<.001)$, engel alt boyutu ile negatif yönlü bir ilişkiye $(\mathrm{r}=.24, \mathrm{p}<.001)$ ve kontrol alt boyutu ile negatif yönlü bir ilişkiye $(r=.25, p<.05)$ işaret etmektedir.

İç Tutarlık Güvenirliği: Ölçeğin iç tutarlığının incelenmesi amacıyla alt boyutların Cronbach Alfa değerleri hesaplanmış, teşvik için .82, kontrol için .77 ve engel için .85 bulunmuştur. Bunun yanı sıra ölçeğin tesadüfi hatalardan arınık olup olmadığını anlamak üzere yarıya bölme iç tutarlık analizi yürütülmüştür. Sonuçlar Guttman güvenirlik katsayılarının teşvik boyutu için .83, kontrol boyutu için .80 ve engel boyutu için .86 olduğunu göstermiştir.

Babalarn Gözünden Anne Bekçiliğinin Demografik Özelliklerle İlişkisi: Babaların algıladığı anne bekçiliği türleri bazı demografik özelliklere göre incelenmiştir. Yürütülen Pearson Çarpım Moment Korelasyon Analizlerine göre, 
ABÖ-B'nin alt boyutlarının ebeveyn yaşı ile ilişkili olmadığı ancak; çocukların yaşı ile babaların algıladığı teşvik düzeyinin negatif yönlü düşük düzeyde $(\mathrm{r}=-.24, \mathrm{p}<.001)$, kontrol ve engel düzeyleriyle ise pozitif yönlü orta düzeyde (sırasıyla: $\mathrm{r}=.72, \mathrm{p}<.05$ ve $\mathrm{r}=.63$, p<.05) ilişkili olduğu görülmüştür. Evlilik süresi ile babaların algıladığı teşvik düzeyinin negatif yönlü düşük düzeyde ( $\mathrm{r}=-$ $.17, \mathrm{p}<.05$ ) ilişkili olduğu görülürken; babaların algıladığı kontrol ve engel düzeylerinin evlilik süresi ile ilişkili olmadığ görülmüştür.

Babaların annelerden algıladığı teşvik düzeyinin çocuk sayısına, çocuk cinsiyetine ve çocukların doğum sırasına göre değişip değişmediği t-test analizleri ile incelenmiştir. Sonuçlara göre birden fazla çocuğu olan babaların eşlerinden algıladıkları teşvik düzeyi daha yüksektir [t(253)=2.39, $\mathrm{p}<.05]$. Ayrıca birden fazla çocuğu olan babalar, yaşı büyük çocukları için daha yüksek düzeylerde teşvik davranışı algılamaktadır $[\mathrm{t}(253)=2.58, \mathrm{p}<.01]$. Bununla birlikte babaların erkek çocukları için algıladıkları teşvik düzeyi, kız çocukları için algıladıkları teşvik düzeyinden daha yüksektir [t(252)=1.99, $\mathrm{p}<.05]$.

Babaların algıladığı anne bekçiliği türlerinin ebeveynlerin eğitim düzeyine (ilkokul-ortaokul, lise, üniversite, lisansüstü) göre değişip değişmediğine algılanan anne bekçiliği türleri (3) x eğitim düzeyi (4) olmak üzere iki ayrı çok değişkenli varyans analizi (MANOVA) ile bakılmıştır. Sonuçlar babaların algıladığı teşvik $[(\mathrm{F}(3,252)=.93, \mathrm{p}>.05]$, kontrol $[(\mathrm{F}(3,252)=.83, \mathrm{p}>.05]$ ve engel $[(F(3,252)=.9,0 \mathrm{p}>.05]$ düzeylerinin kendi eğitim düzeylerine göre farklılaşmadığını göstermiştir. Buna karşın babalar tarafından algılanan bekçilik türlerinden teşvik $[(\mathrm{F}(4,250)=.93, \mathrm{p}<.05]$ düzeyi annelerin eğitim düzeyine göre farklılaşmaktadır. Eşi üniversite ve lisasüstü mezunu olan babalar, eşi ilkokul-ortaokul ve lise mezunu olan babalardan daha yüksek düzeyde teşvik algıladıklarını bildirmişlerdir. Babaların algıladığı kontrol $[(F(4,250)=2.21$, $\mathrm{p}>$.05] ve engel $[(\mathrm{F}(4,250)=.94, \mathrm{p}>.05]$ düzeyleri ise, annelerin eğitim düzeyine göre farklılaşmamıştır.

Anne Bekçiliğinin Sınıflandırılması: Orijinal çalışmadakine uygun olarak (Puhlman ve Pasley, 2013), alt boyutların çaprazlaması yoluyla 8 alt türde anne bekçiliği sınıflandırılması yapılmış ve sıklıkları hesaplanmıştır. Babaların algıladığı anne bekçiliği alt türlerinin sıklığı sırasıyla; \%26.7 ile geleneksel sınır koyucu bekçilik (traditional gateblocker), \%22.4 ile pasif kolaylaştırıcı bekçilik (passive gatewelcomer), \%16.9 ile gözlenmeyen bekçilik (invisible 
gateignorer), \%13.3 ile tutarsız bekçilik (confused gatemanager), \%7.1 ile kolaylaştırıcı bekçilik (faciliatative gateopener), \%5.1 ile pasif sınır koyucu bekçilik (passive gatesnubber) ve \%4.3 ile başına buyruk bekçilik (opinionated gatemanager) ve \%4.2 ile duyarsız bekçiliktir (apathetic gatemanager).

\section{Tartışma ve Sonuç}

Bu çalışmada; babaların eşlerinden algıladığı teşvik edici, kontrolcü ya da engelleyici bekçilik davranışların değerlendirebilmek için Puhlman ve Pasley (2017) tarafından geliştirilen Anne Bekçiliği Ölçeği'nin Baba Formu Türkçeye uyarlanmış, geçerlik güvenirliği incelenmiştir. Çalışmada ölçek geliştirme çalışmalarının yanı sıra, baba çocuk ilişkisini etkilediği bilinen anne bekçiliği davranışları ile baba katılımı arasındaki ilişkilere yönelik ek analizlere yer verilmiştir.

ABÖ-B'nin yapı geçerliğine ilişkin yürütülen doğrulayıcı faktör analizi (DFA), ölçeğin orijinal çalışmada bildirilen üç faktörlü yapıyı (teşvik, kontrol, engel) koruduğunu göstermiştir. Araştırmacılar (Puhlman ve Pasley, 2017) 42 madde üzerinden yürüttükleri DFA'da 15 maddelik bir ölçek elde etmiş ve kontrol ile engel alt boyutları arasında $.80^{\prime}$ lik bir yapısal korelasyon değeri bildirmişlerdir. Mevcut çalışmada ölçeğin toplam madde sayısı 33 (teşvik 10, kontrol 10 ve engel 13) olup ilgili alt boyutlar arasindaki yapisal korelasyon değeri .86 olarak hesaplanmıştır. Orijinal çalışmada da çoklu bağıntı (multicollinearity) sorununa işaret eden araştırmacılar, boyutlar arasındaki ayırt ediciliğin artırılmasının önemli olduğunu vurgulamakla birlikte (Puhlman ve Pasley, 2017); benzer bir çoklu bağıntı sorununa, annelerin bildiriminde de rastlandığı bildirilmiştir (Akgöz-Aktaş ve Aydın, 2020) Araştırmacıların beklentileri ile ters düşen mevcut sonuç, babaların engel ve kontrol maddeleri arasındaki anlam farklarına dikkat etmeksizin; sınılamak, kontrol etmek, engellemek gibi ifadeleri ayn anlamda kabul etmelerine dayanuyor olabilir.

Çalışmanın ölçüt bağıntılı geçerliği, anne bekçilik davranışları ile yakından ilişkili olduğu bilinen baba katılımını ölçen Baba Katılımı Ölçeği (BAKÖ) ile gerçekleştirilmiştir. Bulgulara göre baba katılımı toplam puanı ile babaların algıladığı teşvik arasında orta düzeyde pozitif yönlü, kontrol ve engel ile düşük düzeyde negatif yönlü ilişki saptanmıştır. Sonuçların ölçüt bağıntılı geçerlik için yeterli olmasıyla birlikte, babaların gözünden anne bekçiliği dav- 
ranışlarının baba katılımının alt boyutları ile ilişkileri ayrıntılı olarak incelenmiştir. Burada dikkat çeken birtakım sonuçlar bulunmaktadır. İlk olarak, babaların eşlerinden algıladığı teşvik davranışlarının en yüksek ilişkili olduğu katılım alt boyutunun keyfi meşguliyet olmasıdır. Yani babalar eşlerinden kolaylaştıııcı birtakım bekçilik davranışları algıladığında, çocuklarına katılımlarının oyun ve serbest zaman aktiviteleri kapsamında daha çok arttı̆g görülmüştür. Bir diğer sonuçta, babaların kontrolcü ve engelleyici bekçilik davranışları algıladığında, çocukların günlük ihtiyaçlarının karşılanması ve fiziksel bakımlarının yapılması ile ilgili olan temel bakım boyutunda diğer katılım boyutlarına göre daha yüksek düzeyde düşüş yaşadığı bulunmuştur. Bu iki bulgu, baba katılımının genellikle çocukla oyun aktivitelerinde bulunma olarak ortaya çıtı̆̆ını (Fletcher, StGeorge ve Freeman, 2013; Paquette, 2004) ve çocuk bakımında annenin birincil olarak görev almaya devam ettiğini bildiren geçmiş çalışmalar ile benzerlik göstermektedir (Sayer, Bianchi ve Robinson, 2004). Bir diğer önemli bulgu da, çocuğa karşı duyarlı olup sözel ya da fiziksel olarak sevgi gösterme davranışlarını kapsayan ilgi ve yakınlık katılım boyutunun, babaların algıladığı engelleyici anne bekçiliği davranışları ile ilişkili olmadığının görülmesidir. Dolayısıyla eşler arasındaki ilişki yıprandığında, babaların çocuklar üzerindeki katılım düzeyinin azalarak geri çekilimini ifade eden baba kırılganlığı hipotezinin (Cummings, Merilees ve Ward, 2010; Krishnakumar ve Buehler, 2000) yalnızca annelerin etkisi kapsamında değil; babaların anne davranışlarını algılayışları ve bireysel özellikleri kapsamında genişletilerek incelenmesinin faydalı olacağı düşünülebilir. Aynı zamanda, baba kırılganlığının hangi katılım boyutlarında daha çok yaşandığının araştırılması da bu bağlamda önemli görünmektedir.

Ölçeğe ait alt boyutların iç tutarlık güvenirliklerinin incelenmesi amacıyla Cronbach Alfa güvenirlik katsayıları hesaplanmıştır. Ek olarak yarıya bölme iç tutarlık güvenirlik analizi yürütülmüştür. Ölçeğe ilişkin tüm güvenirlik katsayılarının orijinal çalışmadakiyle uyumlu ve kabul edilebilir sınırlarda olduğu görülmektedir.

Babaların algıladığı bekçilik türlerinin demografik özelliklere göre incelendiği analizlerin Pearson Çarpım Moment Korelasyon sonuçlarına göre, ABÖ-B'nin alt boyutları ile her iki ebeveyn yaşının da ilişkili olmadığı görülmüştür; ancak çocukların yaşı arttıkça babaların algıladığı teşvik düzeyi düşmekte, algıladıkları kontrol ve engel ise artmaktadır. Algılanan bekçilik davranışlarının birden fazla çocuğu olan babalarda nasıl farklılaştığını anlamak 
için yürütülen t-test analizleri, çocuk yaşı ile ilgili bulguyu daha anlamlı kılmaktadır. Birden fazla çocuğu olan babalar yaşı büyük olan çocukları için eşlerinden daha yüksek düzeyde teşvik algılamaktadır. Bu sonuç, çocuk sayısının artması ile birlikte artan ebeveyn sorumluluğunun paylaşılmasında işlevsel bir sonuç olarak görülebilir. Böylece babalar yaşça daha büyük çocukları ile vakit geçirirken, anneler de küçük çocuklarının temel bakımların daha kolay karşılama fırsatı bulabilir. Bu aynı zamanda, Akgöz-Aktaş'ın (2017) birden fazla çocuğu olan babaların ilk çocuklarıyla daha çok vakit geçirdiği bulgusu ile paralel görünmektedir.

Babaların algıladığı bekçilik davranışlarının çocuk cinsiyetine göre nasıl farklılaştığı $\mathrm{T}$ test analizi ile incelendiğinde, babaların erkek çocukları için daha yüksek düzeyde teşvik algıladığı görülmüştür. Annelerin bildirimine dayanan Anne Bekçiliği Ölçeği-Anne Formu'nun uyarlama çalışmasında Akgöz-Aktaş ve Aydın (2020), annelerin kız çocukları için erkek çocuklarına k1yasla daha yüksek düzeyde kontrolcü olduğunu bildirmişlerdir. Diğer bir deyişle anneler, kız çocuklarıyla ilgili eşlerine daha yüksek düzeyde kontrol uyguladıklarını bildirmişlerdir. Karabulut ve Şendil (2017) ise; babaların bildirimine dayanarak geliştirdikleri Anne Bekçiliği Ölçeği'nde, bekçilik ortalamalarının çocuğun cinsiyetine göre değişmediğini bildirmişlerdir. Mevcut çalışmanın çocuk cinsiyeti ile algılanan teşvik alt boyutu ile ilgili anlamlı bulgusu, babaların erkek çocuklarına katılım ve bakım sağlarken kendilerini daha yeterli hissettiklerini bildirdikleri ve ebeveynlerin kız ve erkek çocuklarına farklı biçimlerde duygu sosyalleştirme yaptığını bildiren çalışmalarla (Dunsmore, Halberstadt ve Perez-Rivera, 2009; Garide ve Klimes-Dougan, 2002) ilişkilendirilebilir (Morman ve Floyd, 2002).

Babaların algıladığı bekçilik türlerinin ebeveynlerin eğitim düzeyine göre değişip değişmediğini anlamak için yürütülen çok değişkenli varyans analizi (MANOVA) sonuçları, babaların algıladığı bekçilik alt boyutlarının kendi eğitim düzeylerine göre değişmediğini göstermiştir. Buna karşın babaların algıladığı teşvik düzeyi, annelerin eğitim düzeyine göre farklılaşmıştır. Eşi üniversite ve lisansüstü mezunu olan babaların eşlerinden algıladığı teşvik düzeyi, eşi ilkokul-ortaokul ve lise mezunu olan babalardan daha yüksektir. Karabulut ve Şendil (2017) de babaların bildirimine dayanarak olumsuz özellikteki bekçilik davranışlarını değerlendirdikleri çalışmalarında, lise ve üstü eğitim düzeyine sahip annelerin daha düşük anne bekçiliği ortalamasına sa- 
hip olduğunu bildirmişlerdir. Dahası aynı çalışmada lise ve üstü eğitim düzeyine sahip babaların, anne bekçiliği davranışlarına daha az maruz kaldıkları bulunmuştur. Mevcut çalışma ile benzer olan bu sonuçlar, annelerin eğitim düzeyi arttıkça ailede işbirliği, birlikte ebeveynlik (coparenting) gibi konulara verilen önemin artması ve kadınların geleneksel cinsiyet rollerinden uzaklaşmaları ile açıklanabilir. Aynı zamanda yükselen eğitim düzeyi, babalara daha modern ve esnek bir bakış açısı kazandırarak, daha az gelenekçi bir düşünce yapısı sağlıyor olabilir (Barutçu ve Hıdır, 2016). Buna rağmen, bekçilik davranışlarını annelerin bildirimiyle ölçtükleri çalışmalarında AkgözAktaş ve Aydın (2020), bekçilik alt boyutlarında annelerin eğitim düzeyine göre bir farklılaşma bulamamışlardır. Dolayısıyla bekçilik davranışlarını değerlendirirken, anne ve baba bildirimlerinin farklı sonuçlar verebildiği görülmektedir. $\mathrm{Bu}$, bekçilik davranışlarının bekçiliği uygulayan (anne) ile maruz kalan (baba) kişilerin algısıyla, farklı şekillenebileceğinin de kanıtı niteliğindedir.

Puhlman ve Pasley'in (2013) anne bekçiliği kavramsallaştırmasındaki haline uygun olarak sekiz alt tür bekçilik oluşturulduğunda, babaların en çok algıladıkları alt tür \%26.7 ile geleneksel anne bekçiliği olmuştur. Geleneksel anne bekçiliği düşük teşvik, yüksek kontrol ve yüksek engeli içeren, çoğu zaman babalar için zorlu bir ortam yaratsa da çocukla ilgilenme konusunda zayıf kalan babalar tarafından olumlu karşılanabilen bekçilik türünü ifade eder. Çalışmanın halen ataerkil yapıyı koruduğu bilinen (Pekel-Uludağlı, 2019) Türk aile yapısın temsil eden örnekleme sahip olduğu düşünüldüğünde, babaların geleneksel anne bekçiliğini ifade eden davranışları beklendiği şekliyle olumsuz algılamadığı söylenebilir. Yine de bekçilik alt türlerinin eşler için ne anlama geldiğini anlamak için daha fazla bilgi verici değişkenle çalışılması gerekmektedir.

Sonuç olarak ABÖ-B'nin geçerlik ve güvenirlik analizi bulguları, ölçeğin erken çocukluk döneminde çocuğu olan babaların anne bekçiliği davranışlarına ilişkin algılarını değerlendirmek için uygun olduğunu göstermektedir. Yerel literatürde babaların bekçilik algılarını değerlendirebilecek tek bir ölçek olduğu görülmektedir (Karabulut ve Şendil, 2017). Söz konusu ölçek lise dönemindeki çocukların babaların kapsamakta ve anne bekçiliğinin yalnızca olumsuz özellikle olan davranış kalıplarını içermektedir. Mevcut çalışma, anne bekçiliğini babaların gözünden değerlendirirken daha küçük yaşlardaki çocukların babalarıyla çalışmayı ve bekçilik davranışlarını hem olumlu hem 
olumsuz özellikleri ile birlikte incelemeyi mümkün kılacaktır. Bununla birlikte gelecek anne bekçiliği çalışmalarında, anne ve babaların bildirimlerini birlikte incelemenin çok kıymetli olacağı düşünülmektedir.

\section{Teşekkür}

Assoc. Prof. Daniel Puhlman'a, geliştirmiş olduğu Anne Bekçiliği Ölçeği'ni Türkçeye uyarlamamız için verdiği izin ve süreç boyunca yakın ilgisi için teşekkür ederiz. 


\title{
EXTENDED ABSTRACT
}

\section{Maternal Gatekeeping from Fathers' Perspectives: A Scale Adaptation Study}

\author{
$*$ \\ Güleycan Akgöz Aktaş - Arzu Aydın \\ Mersin University
}

Maternal gatekeeping is commonly defined as facilitating and hindering behaviors of mothers regarding their spouse's participation in family work, especially father-child interaction. Therefore, maternal gatekeeping can be conceptualized as an important 'spouse factor' affecting father involvement. In previous studies to measure maternal gatekeeping, it is seen that measurement tools are often based on mothers' self-reporting or combined mother and father interviews. However, the researchers predicted that parents' perceptions of gatekeeping might differ from each other and reflect differently on parenting practices. The measurement model developed by Puhlman and Pasley in 2013 confirmed that the perception of maternal gatekeeping differs for mothers and fathers. In this model, the researchers found that although the three sub-dimensions of maternal gatekeeping remained the same for each parent, the items representing the sub-dimensions changed. Also, in local literature; it is observed that studies on the concept of maternal gatekeeping are relatively new, and measurement tools are limited. In this study, it is aimed to adapt a valid and reliable scale that evaluates maternal gatekeeping behaviors from fathers' point of view in early childhood and includes the positive and negative features of maternal gatekeeping.

For this purpose, the psychometric properties of the Father Form of The Maternal Gatekeeping Scale (MGS-F) were investigated. Besides, fathers' view of maternal gatekeeping were examined according to some demographic characteristics. A total of 255 fathers with children between the ages of 3 and 7 participated in the study and filled out the demographic information form, Maternal Gatekeeping Scale and Father Involvement Scale.

Confirmatory factor analysis with 42 items showed that the fit indexes of the MGS-F with 33 items (encouragement 10, control 10 and discouragement 13 items) were within acceptable limits. In the analysis, it was found that there 
was a high positive correlation between discouragement and control, a high negative correlation between discouragement and encouragement, and a moderate negative correlation between control and encouragement. A positive correlation was found between the Father Involvement Scale that is used in the criterion validity and the encouragement of the MGS-F, and a negative correlation with the discouragement and control. In order to examine the internal consistency of the scale, the Cronbach Alpha values of the three subdimensions were calculated, and it was found .82 for encouragement, .77 for control and .85 for discouragement. In addition, a split-half internal consistency analysis was conducted to determine whether the scale is free from random errors. The results showed that the Guttman reliability coefficients were .83 for the encouragement, .80 for the control and .86 for the discouragement.

The maternal gatekeeping perceived by fathers were examined according to some demographic characteristics. The results demonstrated that there is no correlation between the three sub-dimensions of MGS-F and the ages of both parents. However, as the age of children increased, control and discouragement perceived by fathers also increased, but encouragement decreased. While it was observed that the duration of the marriage and the perceived encouragement level of fathers were negatively correlated; it has been observed that fathers' perceived levels of control and discouragement are not related to the duration of the marriage. According to the findings, t-test results demonstrated that fathers with more than one child perceive higher levels of encouragement for their older children. This result can be discussed as a functional outcome in sharing parental responsibility that rises with the increase in the number of children. Moreover, it was observed that fathers' perceive higher levels of encouragement for boys. This has been linked to studies that showed that fathers felt more competent in participating and caring for their boys and that parents reported different forms of emotional socialization for their boys and girls (Dunsmore, Halberstadt ve Perez-Rivera, 2009; Garide ve Klimes-Dougan, 2002). Also, MANOVA results showed that the maternal gatekeeping perceived by fathers did not differ according to their education level. On the other hand, the education level of the mothers was found to be related to the encouragement level perceived by the fathers. Fathers whose partners are university and postgraduate perceive higher levels of encouragement from their partners than fathers whose partners are less educated. 
This situation can be explained by the increasing emphasis on family cooperation, co-parenting, and the departure of women from gender roles following the rising level of education.

Finally, regarding the original study (Puhlman \& Pasley, 2013), maternal gatekeeping classifications were made in 8 sub-categories by crossing the three sub-dimensions and their frequencies were calculated. $26.7 \%$ of the subcategories of the most common type of maternal gatekeeping perceived by fathers were found to be traditional gate-blocker. Considering that the study has a sample representing the Turkish family structure known to have a patriarchal structure (Pekel-Uludağl1, 2019), it may be usual for fathers to perceive traditional gate-blocker most often. Still, it is necessary to work with more informative variables to understand what the sub-types of the maternal gatekeeping mean for spouses.

In conclusion, the findings show that the scale is valid and reliable for evaluating the perceptions of fathers who have children in early childhood regarding maternal gatekeeping. The present study will make it possible to work with fathers who have preschool aged children while evaluating maternal gatekeeping from the perspectives of fathers and examining gatekeeping behaviors with both positive and negative features.

\section{Appreciation}

We thank Assoc. Prof. Daniel Puhlman for his permission to adapt the Maternal Gatekeeping Scale into Turkish and for his close interest throughout the process.

\section{Kaynakça / References}

Adamsons, K. (2010). Using identity theory to develop a midrange model of parental gatekeeping and parenting behavior. Journal of Family Theory \& Review, 2(2), 137-148.

Akgöz-Aktaş, G. (2017). Baba katılımı ve çocuk uyumu arasındaki ilişkinin incelenmesi: anne bekçiliği ve evlilik uyumunun etkisi. Yayımlanmamış yüksek lisans tezi. Mersin Üniversitesi Sosyal Bilimler Enstitüsü, Mersin.

Akgöz-Aktaş, G. ve Aydın, A. (2020). Anne bekçiliği ölçeği anne formunun Türkçeye uyarlanması: Geçerlik ve güvenirlik çalışması. Türk Psikoloji Yazıları, 23(45), 63-77. 
Allen, S. M., ve Daly, K. J. (2007). The effects of father involvement: An updated research summary of the evidence. Centre for Families, Work \& Well-Being, University of Guelph.

Allen, S. M., ve Hawkins, A. J. (1999). Maternal gatekeeping: Mothers' beliefs and behaviors that inhibit greater father involvement in family work. Journal of Marriage and the Family, 199-212.

Altenburger, L. E., Schoppe-Sullivan, S. J., ve Dush, C. M. K. (2018). Associations between maternal gatekeeping and fathers' parenting quality. Journal of Child and Family Studies, 27(8), 2678-2689.

Aydın, A., ve Akgöz-Aktaş G. (2017) Anne bekçiliği üzerine bir derleme. Çocuk ve Gençlik Ruh Să̆ğı̆̆ Dergisi, 24 (3), 283-292.

Barutçu, A., ve Hıdır, N. (2016). Türkiye'de Babalığın Değişen Rolleri: (Pro) Feminist Babalar. Fe Journal: Feminist Critique/Fe Dergi: Feminist Eleştiri, 8(2).

Bouchard, G., Lee, C. M., Asgary, V., \& Pelletier, L. (2007). Fathers' motivation for involvement with their children: A self-determination theory perspective. $\mathrm{Fa}$ thering-Harriman-, 5(1), 25.

Cabrera, N., Fitzgerald, H. E., Bradley, R. H., ve Roggman, L. (2007). Modeling the dynamics of paternal influences on children over the life course. Applied Development Science, 11(4), 185-189.

Carrillo, S., Bermúdez, M., Gutiérrez, L. S., Camila, M., ve Delgado, X. (2016). Father's Perceptions of their Role and Involvement in the Family: A Qualitative Study in a Colombian Sample. Revista Costarricense de Psicología, 35(2), 37-54.

Cox, M. J., ve Paley, B. (2003). Understanding families as systems. Current directions in psychological science, 12(5), 193-196.

Cummings, E. M., Goeke-Morey, M. C., ve Raymond, J. (2004). Marital quality and conflict are related to children's functioning and adjustment 2001. The role of the father in child development, 196.

Cummings, E. M., Merrilees, C. E., \& Ward, M. (2010). Fathers, marriages, and families. The role of the father in child development, 154-176.

Çoban, İ. (2017). The effect of maternal gatekeeping on shared past conservations through father involvement. Yayımlanmamış yüksek lisans tezi. Ortadoğu Teknik Üniversitesi, Psikoloji Bölümü, Ankara.

DeLuccie, M. F. (1995). Mothers as gatekeepers: A model of maternal mediators of father involvement. The Journal of Genetic Psychology, 156, 115-131.

Dickie, J. (1987). Interrelationships within the mother-father-infant triad. I: Pedersen $\mathrm{F}$, red. Men's transitions to parenthood. Longitudinal studies of early family experience. 
Downer, J., Campos, R., McWayne, C., ve Gartner, T. (2008). Father involvement and children's early learning: A critical review of published empirical work from the past 15 years. Marriage \& Family Review, 43(1-2), 67-108.

Downer, J. T., ve Mendez, J. L. (2005). African American father involvement and preschool children's school readiness. Early Education and Development, 16(3), 317-340.

Dunsmore, J. C., Her, P., Halberstadt, A. G., ve Perez-Rivera, M. B. (2009). Parents' beliefs about emotions and children's recognition of parents'emotions. Journal of nonverbal behavior, 33(2), 121-140.

Durrett, M. E., Richards, P., Otaki, M., Pennebaker, J. W., ve Nyquist, L. (1986). Mother's involvement with infant and her perception of spousal support, Japan and America. Journal of Marriage and the Family, 187-194.

Evenson, R. J., ve Simon, R. W. (2005). Clarifying the relationship between parenthood and depression. Journal of health and Social Behavior, 46(4), 341-358.

Fagan, J., ve Barnett, M. (2003). The relationship between maternal gatekeeping, paternal competence, mothers' attitudes about the father role, and father involvement. Journal of family issues, 24(8), 1020-1043.

Fagan, J., Cherson, M., Brown, C., ve Vecere, E. (2015). Pilot study of a program to increase mothers' understanding of dads. Family process, 54(4), 581-589.

Fletcher, R., StGeorge, J., ve Freeman, E. (2013). Rough and tumble play quality: Theoretical foundations for a new measure of father-child interaction. Early Child Development and Care, 183(6), 746-759.

Fogarty, K., ve Evans, G. D. (2009). The hidden benefits of being an involved father. Department of Family, Youth and Community Sciences, Florida Cooperative Extension Service, Institute of Food and Agricultural Sciences, University of Florida.

Garside, R. B., ve Klimes-Dougan, B. (2002). Socialization of discrete negative emotions: Gender differences and links with psychological distress. Sex roles, 47(3-4), 115-128.

Gaunt, R. (2008). Maternal gatekeeping: Antecedents and consequences. Journal of family issues, 29(3), 373-395.

Gazi, T. (2019). Annelik bekçiliği ve evlilik uyumunun baba katılımı ve baba-ergen ilişkilerindeki rolünün incelenmesi. Yayımlanmamış yüksek lisans tezi. Maltepe Üniversitesi Sosyal Bilimler Enstitüsü, İstanbul.

Geeraerts, S. B., Backer, P. M., ve Stifter, C. A. (2020). It takes two: Infants' moderate negative reactivity and maternal sensitivity predict self-regulation in the preschool years. Developmental psychology. 
Hawkins, D. N., Amato, P. R., ve King, V. (2007). Nonresident father involvement and adolescent well-being: Father effects or child effects?. American Sociological Review, 72(6), 990-1010.

Hawkins, A. J., ve Dollahite, D. C. (1997). Beyond the role-inadequacy perspective of fathering.

Henwood, K., ve Procter, J. (2003). The 'good father': Reading men's accounts of paternal involvement during the transition to first-time fatherhood. British Journal of Social Psychology, 42(3), 337-355.

Hoffmaster, B. (2006). What does vulnerability mean?. Hastings Center Report, 36(2), 38-45.

Ishii-Kuntz, M., Gomel, J. N., Tinsley, B. J., ve Parke, R. D. (2010). Economic hardship and adaptation among Asian American families. Journal of Family Issues, 31(3), 407-420.

Jia, R., ve Schoppe-Sullivan, S. J. (2011). Relations between coparenting and father involvement in families with preschool-age children. Developmental Psycho$\log y, 47(1), 106$.

Karabulut, H. ve Şendil, G. (2017). Annelik Bekçiliği Ölçeği'Nin (ABÖ) Türkçeye Uyarlanmas1. Electronic Journal of Social Sciences, 16(61).

Katz, R., ve Lavee, A. (2004). Y. (2005). Families in Israel. Handbook of world families, 486-506.

Kennedy, M., Betts, L., Dunn, T., Sonuga-Barke, E., ve Underwood, J. (2015). Applying Pleck's model of paternal involvement to the study of preschool attachment quality: a proof of concept study. Early Child Development and Care, 185(4), 601-613.

Kiang, L., Moreno, A. J., ve Robinson, J. L. (2004). Maternal preconceptions about parenting predict child temperament, maternal sensitivity, and children's empathy. Developmental Psychology, 40(6), 1081.

Krishnakumar, A., ve Buehler, C. (2000). Interparental conflict and parenting behaviors: A meta-analytic review. Family relations, 49(1), 25-44.

Kuo, P. X., Volling, B. L., ve Gonzalez, R. (2018). Gender role beliefs, work-family conflict, and father involvement after the birth of a second child. Psychology of men $\mathcal{E}$ masculinity, 19(2), 243.

Kurşun, G. (2019). Baba katılımı ve annelik bekçiliği davranışının algılanan baba kabul-reddi ile ilişkisininin incelenmesi. Master's thesis, Maltepe Üniversitesi, Sosyal Bilimler Enstitüsü.

Lamb, M. E. (2000). The history of research on father involvement: An overview. Marriage \& Family Review, 29(2-3), 23-42. 
Lamb, M. E., Pleck, J. H., ve Levine, J. A. (1985). The role of the father in child development. In Advances in clinical child psychology (p. 229-266). Springer, Boston, MA.

Marsiglio, W. (1993). Contemporary scholarship on fatherhood culture,identity, and conduct. Journal of Family Issues, 14(4), 484-509.

McBride, B. A., Brown, G. L., Bost, K. K., Shin, N., Vaughn, B., ve Korth, B. (2005). Paternal identity, maternal gatekeeping, and father involvement. Family relations, 54(3), 360-372.

Mehall, K. G., Spinrad, T. L., Eisenberg, N., ve Gaertner, B. M. (2009). Examining the relations of infant temperament and couples' marital satisfaction to mother and father involvement: a longitudinal study. Fathering, 7 (1), 23-48.

Meteyer, K., ve Perry-Jenkins, M. (2010). Father involvement among working- class, dual-earner couples. Fathering, 8(3), 379.

Morman, M. T., ve Floyd, K. (2002). A "changing culture of fatherhood": Effects on affectionate communication, closeness, and satisfaction in men's relationships with their fathers and their sons. Western Journal of Communication (includes Communication Reports), 66(4), 395-411.

Paquette, D. (2004). Theorizing the father-child relationship: Mechanisms and developmental outcomes. Human development, 47(4), 193-219.

Pedersen, F. A., ve Berman, P. W. (Eds.). (1987). Men's Transitions to Parenthood: Longitudinal Studies of Early Family Experience. L. Erlbaum Associates.

Pekel-Uludağlı, N. (2019). Are uninvolved fathers really incompetent and unsatisfied? Testing the mediator role of father involvement from fathers' perspectives. European Journal of Developmental Psychology, 16(5), 538-551.

Petter, O. (2018, Mart 16). Being a Mother is Equivalent to 2.5 Full-Time Jobs, Survey Finds. Independents. 6 Nisan 2020 tarihinde https://www.independent.co.uk/ adresinden erişildi.

Pleck, J. H., ve Masciadrelli, B. P. (2004). Paternal involvement by US residential fathers: Levels, sources, and consequences.

Puhlman, D. J. (2013). Developing and testing a comprehensive measure of maternal gatekeeping. Doktora tezi, Florida State University. DigiNole veri tabanindan erişildi. (Tez numarası 7559).

Puhlman, D. J., ve Pasley, K. (2013). Rethinking maternal gatekeeping. Journal of family theory \& review, 5(3), 176-193.

Puhlman, D. J., ve Pasley, K. (2017). The maternal gatekeeping scale: constructing a measure. Family Relations, 66(5), 824-838. 
Van Egeren, L. A., ve Hawkins, D. P. (2004). Coming to terms with coparenting: Implications of definition and measurement. Journal of Adult Development, 11(3), 165-178.

Walker, A. J., ve McGraw, L. A. (2000). Who is responsible for responsible fathering?. Journal of Marriage and family, 62(2), 563-569.

Sarkadi, A., Kristiansson, R., Oberklaid, F., ve Bremberg, S. (2008). Fathers' involvement and children's developmental outcomes: A systematic review of longitudinal studies. Acta paediatrica, 97(2), 153-158.

Sayer, L. C., Bianchi, S. M., ve Robinson, J. P. (2004). Are parents investing less in children? Trends in mothers' and fathers' time with children. American journal of sociology, 110(1), 1-43.

Schoppe-Sullivan, S. J., Brown, G. L., Cannon, E. A., Mangelsdorf, S. C., ve Sokolowski, M. S. (2008). Maternal gatekeeping, coparenting quality, and fathering behavior in families with infants. Journal of Family Psychology, 22(3), 389.

Sımsıkı, H., ve Şendil, G. (2014). Baba Katılım Ölçeği'nin (BAKÖ) Geliştirilmesi. Elektronik Sosyal Bilimler Dergisi, 13(49), 104-123.

Silverstein, L. B., Auerbach, C. F., ve Levant, R. F. (2002). Contemporary fathers reconstructing masculinity: Clinical implications of gender role strain. Professional Psychology: Research and Practice, 33(4), 361.

\section{Kaynakça Bilgisi / Citation Information}

Akgöz Aktaş, G. ve Aydın, A. (2020). Babaların gözünden anne bekçiliği: Bir ölçek uyarlama çalışması. OPUS-Uluslararası Toplum Araştırmaları Dergisi, 16(Özel Say1), 3565-3590. DOI: 10.26466/opus.724644 